University of Wollongong

Research Online

Faculty of Engineering and Information

Faculty of Engineering and Information

Sciences - Papers: Part B

Sciences

2020

Fate of titanium in alkaline electro-reduction of sintered titanomagnetite

Oscar Bjareborn

Tanzeel Arif

Brian J. Monaghan

University of Wollongong, monaghan@uow.edu.au

Christopher W. Bumby

Follow this and additional works at: https://ro.uow.edu.au/eispapers1

Part of the Engineering Commons, and the Science and Technology Studies Commons

Research Online is the open access institutional repository for the University of Wollongong. For further information contact the UOW Library: research-pubs@uow.edu.au 


\title{
Fate of titanium in alkaline electro-reduction of sintered titanomagnetite
}

\author{
Abstract \\ Direct electrochemical reduction of iron ore in concentrated $\mathrm{NaOH}$ electrolyte has been proposed as a \\ potential route to substantially reducing the global steel industry's $\mathrm{CO} 2$ emissions. Here, we report the \\ solid-state electro-reduction of sintered pellets formed from titanomagnetite ironsand. This commercial \\ iron ore contains $\sim 4 \mathrm{wt}$ \% Ti which is directly incorporated within the magnetite lattice. At $110{ }^{\circ} \mathrm{C}$, these \\ pellets are electrochemically reduced and exhibit a well-defined reaction front which moves into the pellet \\ as the reaction progresses. The electro-reduction process selectively produces iron metal, whilst the $\mathrm{Ti}$ \\ content is not reduced. Instead, Ti becomes enriched in segregated oxide inclusions, which are \\ subsequently transformed to a sodium iron titanate phase through taking up $\mathrm{Na}+$ from the electrolyte. \\ These inclusions adopt an elongated shape and appear to exhibit locally preferential alignment. This \\ suggests that they may nucleate from the microscopic titanohematite lamellae which naturally occur \\ within the original ironsand particles. The expulsion of contaminant Ti-oxides from the final reduced \\ metal matrix has implications for the potential to development of an industrial electrochemical iron- \\ making process utilising titanomagnetite ore.

\section{Disciplines} \\ Engineering | Science and Technology Studies \\ Publication Details \\ Bjareborn, O., Arif, T., Monaghan, B. \& Bumby, C. W. (2020). Fate of titanium in alkaline electro-reduction of \\ sintered titanomagnetite. Materials Research Express, 7 (10).
}


PAPER • OPEN ACCESS

Fate of titanium in alkaline electro-reduction of sintered titanomagnetite To cite this article: Oscar Bjareborn et al 2020 Mater. Res. Express 7106508

\section{9th ECS Meeting}

with the 18th International Meeting on Chemical Sensors (IMCS)

ABSTRACT DEADLINE: DECEMBER 4, 2020

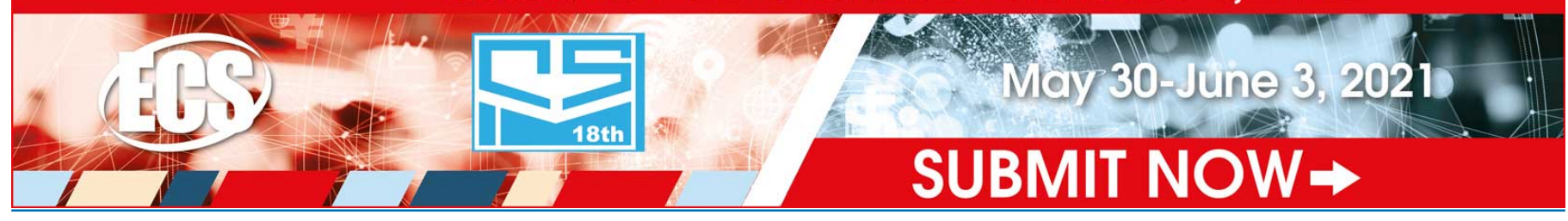

This content was downloaded from IP address 220.233 .176 .58 on 17/11/2020 at 21:38 
PAPER

CrossMark

\section{Fate of titanium in alkaline electro-reduction of sintered titanomagnetite}

RECEIVED

7 September 2020

REVISED

24 September 2020

ACCEPTED FOR PUBLICATION

30 September 2020

PUBLISHED

9 October 2020

Original content from this

work may be used under

the terms of the Creative

Commons Attribution 4.0

licence.

Any further distribution of this work must maintain

attribution to the

author(s) and the title of

the work, journal citation

and DOI.

\author{
Oscar Bjareborn ${ }^{1}$, Tanzeel Arif ${ }^{1}$ (D), Brian Monaghan ${ }^{2}$ (D) and Chris W Bumby ${ }^{1,3, *}$ (D) \\ 1 Robinson Research Institute, Faculty of Engineering, Victoria University of Wellington, Lower Hutt 5046, New Zealand \\ 2 Department of Materials Engineering, University of Wollongong, Wollongong, NSW 2522, Australia \\ 3 The MacDiarmid Institute of Advanced Materials and Nanotechnology, Victoria University of Wellington, New Zealand \\ Author to whom any correspondence should be addressed. \\ E-mail: chris.bumby@vuw.ac.nz
}

Keywords: titanomagnetite electrolysis, alkaline electrolyte, iron electrowinning, ceramic cathode

\begin{abstract}
Direct electrochemical reduction of iron ore in concentrated $\mathrm{NaOH}$ electrolyte has been proposed as a potential route to substantially reducing the global steel industry's $\mathrm{CO}_{2}$ emissions. Here, we report the solid-state electro-reduction of sintered pellets formed from titanomagnetite ironsand. This commercial iron ore contains $\sim 4 \mathrm{wt} . \%$ Ti which is directly incorporated within the magnetite lattice. At $110^{\circ} \mathrm{C}$, these pellets are electrochemically reduced and exhibit a well-defined reaction front which moves into the pellet as the reaction progresses. The electro-reduction process selectively produces iron metal, whilst the Ti content is not reduced. Instead, Ti becomes enriched in segregated oxide inclusions, which are subsequently transformed to a sodium iron titanate phase through taking up $\mathrm{Na}^{+}$from the electrolyte. These inclusions adopt an elongated shape and appear to exhibit locally preferential alignment. This suggests that they may nucleate from the microscopic titanohematite lamellae which naturally occur within the original ironsand particles. The expulsion of contaminant Ti-oxides from the final reduced metal matrix has implications for the potential to development of an industrial electrochemical iron-making process utilising titanomagnetite ore.
\end{abstract}

\section{Introduction}

Iron and steelmaking is responsible for $7 \%$ of total global $\mathrm{CO}_{2}$ emissions [1], making it the second largest industrial source. As a result, there is growing global interest in alternative iron-making processes with reduced emissions [2,3]. One such approach is the electrowinning of iron [4-7] using electricity generated from renewable sources. Pyro-electrolysis of iron oxides can be achieved at high temperatures in molten electrolytes [8-10]. Alternatively, electroreduction can also take place in alkaline hydroxide solutions at temperatures below $150{ }^{\circ} \mathrm{C}[11-14]$. This latter approach is attractive, as the lower process temperature enables a wider choice of anode materials. Whilst alkaline electrowinning approaches have been studied for magnetite $\left(\mathrm{Fe}_{3} \mathrm{O}_{4}\right)$ and hematite $\left(\mathrm{Fe}_{2} \mathrm{O}_{3}\right)$ feedstocks, there is little known about the applicability of this process to other forms of iron ore. One such ore is Titanomagnetite (TTM) which is commercially utilised as a steel-making feedstock in several countries $[15,16]$. TTM has the stoichiometric form, $\mathrm{Fe}_{3-x} \mathrm{Ti}_{x} \mathrm{O}_{4}$, and adopts the same crystal structure as magnetite. However, ironmaking from TTM ore is not entirely straightforward, as the titanium content prevents it from being processed via the traditional blast furnace route. This is due to the formation of a high viscosity Ticontaining slags which blocks the furnace [17]. Instead, TTM is commercially smelted using $\mathrm{CO}_{2}$-intensive direct reduction methods [18], which employ coal as both the thermal fuel and chemical reductant. In principle, an alternative electro-reduction process could simultaneously decrease $\mathrm{CO}_{2}$ emissions and also circumvent the problems of processing Ti-bearing slags.

It has previously been shown that solid-state electro-reduction of iron oxides can be achieved in concentrated alkaline solutions, which are well suited to fostering the required anodic evolution of oxygen [19-21]. This approach has been used to electrochemically reduce both conductive iron oxide cathodes [22-24], 


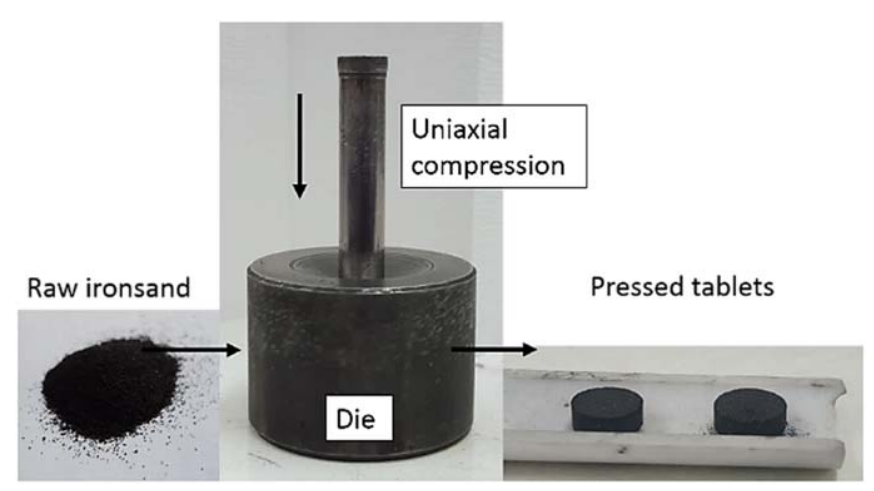

Figure 1. Schematic showing pellet preparation method by uniaxial compression of ironsand in a die.

and also agitated slurries of fine iron ore particles in suspension $[5,11,19,21,25,26]$. However, the mechanism by which these reactions proceed remains a matter of some conjecture. Ionic Fe species are very poorly soluble in alkaline electrolytes, but some authors have nonetheless suggested that continuous dissolution and redeposition of Fe ions may occur at the cathode [12, 22, 23, 27]. In contrast, others have described a solid-state electrodeoxidation of the iron oxide, similar to the FFC Cambridge process [19-21,28]. Evidence for this latter mechanism includes the observation of a well-defined reaction front at both microscopic [19, 20] and macroscopic scales [23].

TTM possesses the same crystal structure and Fe oxidation states as magnetite, so might be expected to follow a similar electro-reduction pathway. However, TTM is more thermodynamically stable than non-titaniferous magnetite [29-32], and the role and fate of $\mathrm{Ti}^{4+}$ during alkaline electroreduction has not previously been studied. This paper describes an experimental study into the feasibility of alkaline electroreduction of TTM ironsand, and the fate of titanium species during this process. Sintered TTM pellets have been employed as the cathode electrode in these experiments, and the electrochemical reactions taking place within these pellets have been studied to provide insights into the mechanism of electroreduction, and the fate of contaminants in the iron ore.

The TTM ironsand used in this work has been sourced from New Zealand, which has abundant deposits of chemically uniform ironsand, containing approximately $8 \% \mathrm{TiO}_{2}$ by mass [33-36]. Similar ironsands are also found in other large deposits in the South Pacific [35-37].

\section{Experimental}

New Zealand titanomagnetite ironsand concentrate was commercially sourced from Industrial Sands Ltd (Waikato North Head). Samples were washed in water to remove impurity fines, and then sieved to produce a particle size fraction of 125-150 $\mu \mathrm{m}$ which was used throughout this work. Ironsand pellets were prepared by uniaxial pressing at $35 \mathrm{MPa}$ in a die with an inner diameter of $10 \mathrm{~mm}$, using a hydraulic press. A schematic of this process is shown in figure 1 . The pellets were then sintered at $1300{ }^{\circ} \mathrm{C}$ for $2 \mathrm{~h}$ in an argon atmosphere. Each pellet was mechanically thinned (i.e. polished) to a thickness of $1.5 \mathrm{~mm}$, then washed in distilled water and ethanol, and dried in a flow of clean air.

Electrochemical reduction of these ironsand pellets was studied using the experimental configuration presented in figure 2. The working electrode comprised a stainless-steel rod (SS316L), to which the ironsand pellet was mounted using silver conductive paint. The steel rod was electrically insulated with polytetrafluoroethylene (PTFE) film tape and shrink tubing. This left only the top surface of the ironsand pellet exposed to the electrolyte, forming an electroactive surface area for the working electrode of $78.5 \mathrm{~mm}^{2}$. The anode was a platinised titanium mesh cylinder, which surrounded the working electrode in order to minimise electrolyte resistance. Three-electrode studies were carried out using a $\mathrm{Hg} \mid \mathrm{HgO}(20 \% \mathrm{KOH})$ reference electrode $\left(+0.098 \mathrm{~V}\right.$ versus $\mathrm{NHE}$ at $\left.110^{\circ} \mathrm{C}\right)$. To avoid contamination, the reference electrode compartment was connected to the electrolyte via a sintered junction extension filled with $20 \% \mathrm{KOH}$. This three-electrode configuration was connected to a potentiostat (Metrohm Autolab) controlled by PC software (NOVA 2.1). Cyclic voltammograms (CV) were recorded at a scan rate of $20 \mathrm{mV} \mathrm{s}^{-1}$, starting from the open circuit potential $\left(\mathrm{E}_{\mathrm{oc}}\right)$, and following the scheme $\mathrm{E}_{\mathrm{oc}} \rightarrow-1.3 \mathrm{~V} \rightarrow-0.3 \mathrm{~V}$, unless indicated otherwise.

Electro-reduction experiments were performed in a stirred alkaline electrolyte ( $\left.50 \mathrm{wt} \% \mathrm{NaOH}-\mathrm{H}_{2} \mathrm{O}\right)$, which was contained within a PTFE beaker heated in a heated silicone oil bath. Systematic CV experiments were performed at 50,80 and $110^{\circ} \mathrm{C}$ on ironsand pellets. After reduction, the ironsand pellet was removed, rinsed in distilled water and dried in a vacuum oven at $80^{\circ} \mathrm{C}$. XRD analysis of the top surface of the reduced pellets was 


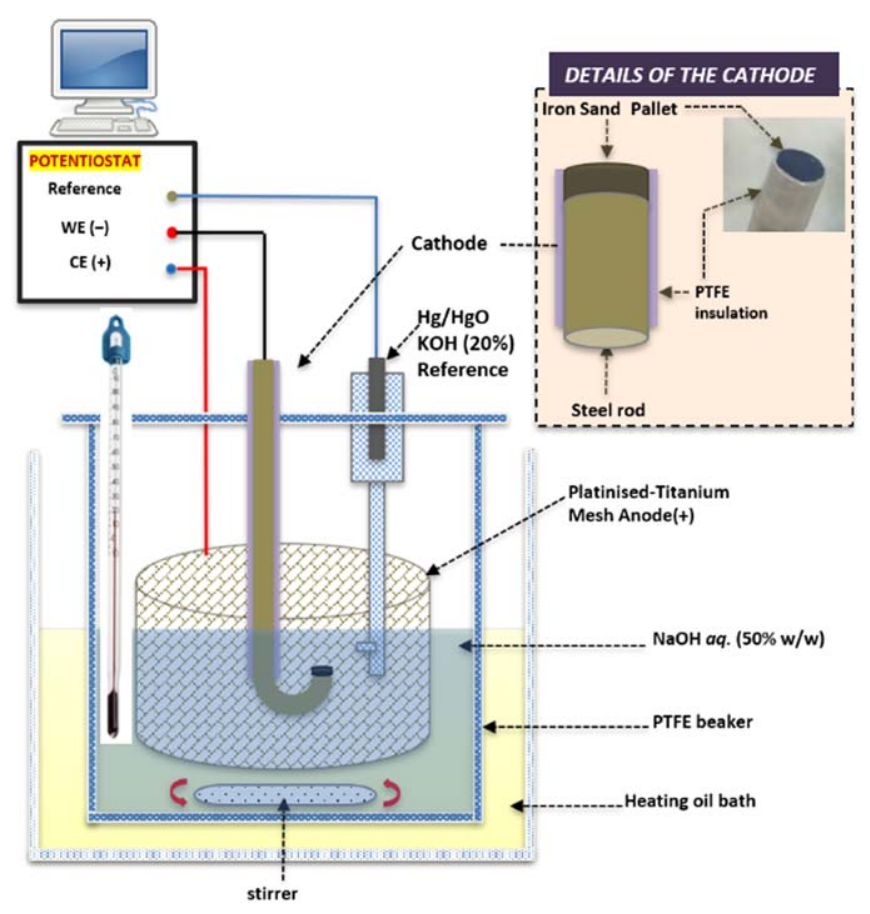

Figure 2. Schematic diagram of the electrochemical cell used in this work

performed to verify the presence of metallic iron. X-ray diffraction (XRD) spectra were recorded employing a Bruker D8 Advance diffractometer with Co-K $\alpha$ (Cobalt (Co): $6.9257 \mathrm{keV}, \lambda=1.7902 \AA)$. The pellets were then set in an epoxy resin and a cross section was polished for SEM analysis. Morphology and microstructural features were characterized by SEM and EDS using a FEI Quanta 450 and a FEI Nano-SEM Nova 450 (both equipped with EDAX EDS detectors).

\section{Results and discussion}

\subsection{Fabrication and characterization of ironsand pellets}

NZ ironsand is a well-studied mineral which is known to consist mostly of homogeneous spheroidal particles of TTM $[33,38]$. A small amount of titano-hematite (TTH) is also present in the form of lamellae observed within a minority of particles [34, 39]. TTH is a solid solution within the hematite-ilmenite $\left(\mathrm{Fe}_{2} \mathrm{O}_{3}-\mathrm{FeTiO}_{3}\right)$ series.

The naturally occurring TTH lamella contain substantially higher levels of Ti than the surrounding TTM matrix (see figure 3(c)). Elemental composition of the naturally occurring ironsand studied in this work was analysed by X-ray fluorescence and is given in table 1 . With the exception of Fe, composition is given as equivalent wt.\% of the common oxide. In addition to TTM, appreciable levels of $\mathrm{Al}, \mathrm{Si}$ and $\mathrm{Mg}$ are also found to be present. SEM-EDS (not shown) indicates that whilst silicates are largely present as discrete gangue inclusions, both $\mathrm{Al}$ and $\mathrm{Mg}$ enter solid-solution within the TTM crystal lattice.

The porosity of the sintered pellets was measured using the Archimedes' principle, and indicated an open porosity of 15\%-20\%. SEM analysis of a cross-section of sintered pellet before reduction is presented in figure 4 . This shows a well sintered pellet with multiple inter-particle bonds formed by 'necking' between neighbouring particles. Some variation in titanium content is observed across the pellet, in the form of fine lamellar features (assumed to be TTH), as well as a small number of individual grains with relatively high titanium content. Figure 5 shows XRD patterns obtained from both the raw ironsand powder, and from a pellet sintered under argon atmosphere for $24 \mathrm{~h}$ at $1300{ }^{\circ} \mathrm{C}$. The sintered pellet shows a small increase of the amplitude of hematite peaks compared to the initial ironsand sample, which indicates some thermal transformation of TTM to titanohematite during the sintering process [40]. However, titanomagnetite remains the dominant phase present after sintering process.

\subsection{Electrochemical behaviour of ironsand pellets in $\mathrm{NaOH} 50 \mathrm{wt} \%$ solution}

Initial electrochemical experiments were performed to investigate the electrochemical behaviour of the ironsand in strong alkaline electrolyte. The temperature range studied in current manuscript is consistent with temperature range for conventional magnetite electrowinning in literature [8]. This temperature range is also 


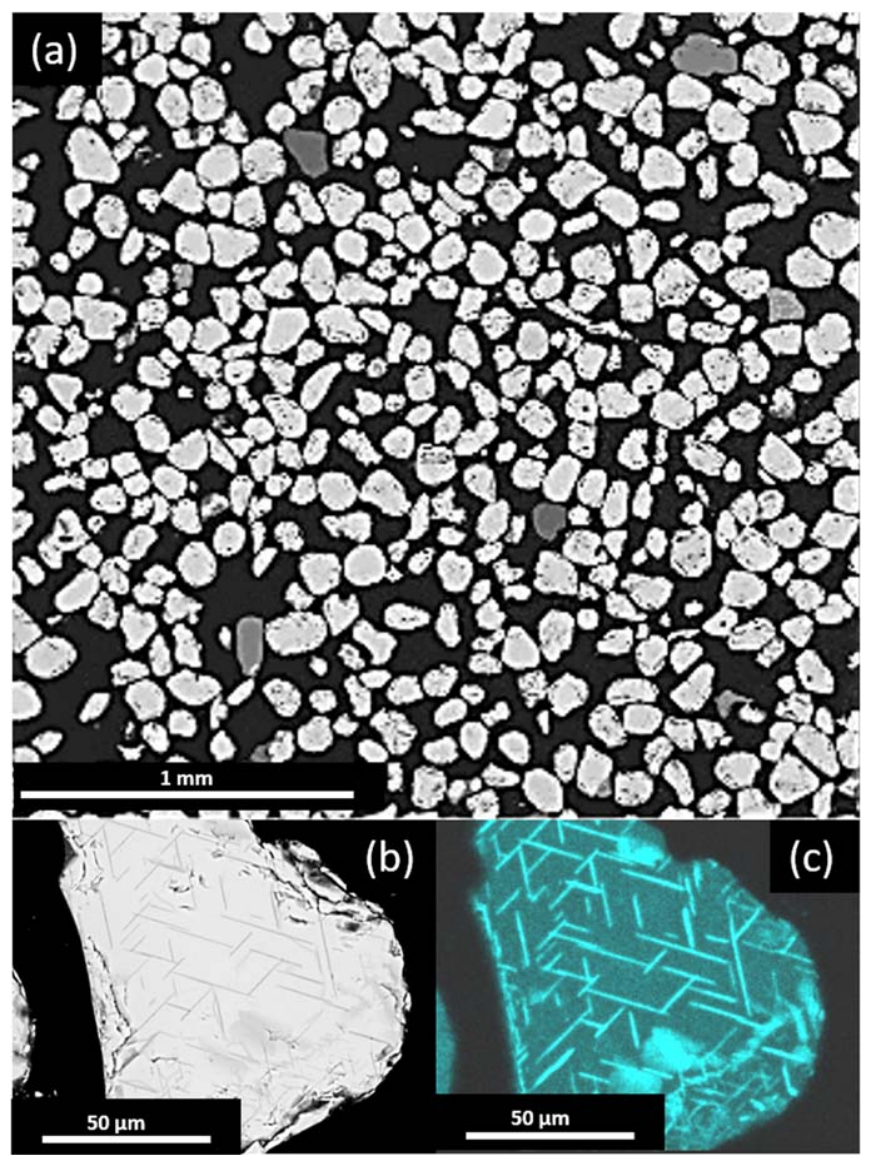

Figure 3. Back-scatter SEM images of a polished cross-section of NZ ironsand (125-150 $\mu \mathrm{m})$. Darker grey grains in the image (a) are 'gangue' particles containing lower concentration of Fe. The image (b) shows a single TTM particle containing exsolved TTH lamellae. Titanium concentration within these lamellae is shown by inset EDS-map (c).

Table 1. XRF analysis of the TTM ironsand, obtained after initial roasting in air at $1000{ }^{\circ} \mathrm{C}$ for $1 \mathrm{~h}$. $\mathrm{LOI}=$ mass loss after roasting, where negative value indicates sample gained mass due to oxygen take-up during roast step.

\begin{tabular}{|c|c|c|c|c|c|c|c|c|c|}
\hline & $\mathrm{Fe}^{\mathrm{a}}$ & $\mathrm{TiO}_{2}$ & $\mathrm{Al}_{2} \mathrm{O}_{3}$ & $\mathrm{MgO}$ & $\mathrm{SiO}_{2}$ & $\mathrm{~V}_{2} \mathrm{O}_{5}$ & $\mathrm{MnO}_{2}$ & Other & LOI \\
\hline $\mathrm{wt} \%$ & 59.1 & 7.9 & 3.8 & 2.8 & 2.0 & 0.6 & 0.6 & 0.69 & -3 \\
\hline
\end{tabular}

${ }^{\text {a }}$ Calculated from equiv. $\mathrm{Fe}_{2} \mathrm{O}_{3}$ value in fully oxidised sample.

suitable for electrolyte stability and furthermore avoids the water loss which can occur at higher temperatures. Figure 6 shows cyclic voltammetry $(\mathrm{C}-\mathrm{V})$ curves obtained from the ironsand pellet electrodes at three different temperatures, during cyclic scanning between $-0.3 \mathrm{~V}$ and $-1.3 \mathrm{~V}$ (relative to a $\mathrm{Hg} / \mathrm{HgO}$ reference electrode). In each case the first 2 full cycles are shown. At $50{ }^{\circ} \mathrm{C}$, cathodic peaks $\mathrm{C}_{1}$ and $\mathrm{C}_{2}$ are observed during the first potential scan in the cathodic direction. Further negative polarization beyond $\mathrm{C}_{2}$ gives rise to a rapidly increasing cathodic current $\mathrm{B}$. At $80^{\circ} \mathrm{C}$ and $110^{\circ} \mathrm{C}$ the cathodic peak $\mathrm{C}_{2}$ is present, but $\mathrm{C}_{1}$ is only revealed as a masked shoulder. In addition, two anodic peaks were obtained at 50 and $80^{\circ} \mathrm{C}, \mathrm{A}_{1}(\sim-0.5 \mathrm{~V})$ and $\mathrm{A}_{2}(\sim-0.9 \mathrm{~V})$, but only $\mathrm{A}_{2}$ was observed at $110^{\circ} \mathrm{C}$.

The $\mathrm{C}-\mathrm{V}$ curves shown in figure 6 are very similar to those reported previously in conventional magnetite studies $[8,20,21,41]$. We therefore attribute the peak $\mathrm{C}_{1}$ to partial reduction of $\mathrm{Fe}(\mathrm{III})$ to $\mathrm{Fe}$ (II) species and peak $\mathrm{C}_{2}$ to reduction of $\mathrm{Fe}(\mathrm{II})$ to metallic $\mathrm{Fe}$. It is of note that distinct differences were observed in the nature of the $\mathrm{C}_{2}$ peak during the first cycle on a virgin pellet, versus all subsequent cycles. During the first cycle, Fe metal is initially reduced from the TTM matrix. As the cycle returns through the anodic peaks $\left(\mathrm{A}_{1}\right.$ and $\left.\mathrm{A}_{2}\right)$ this Fe metal is then electrochemically re-oxidised to form a surface iron hydroxide [42]. This newly formed hydroxide then participates in all subsequent cycles, masking any subsequent peaks arising from reduction of the TTM matrix. In addition to basic thermodynamic considerations [43], the electrical conductivity of magnetite and solid-state 


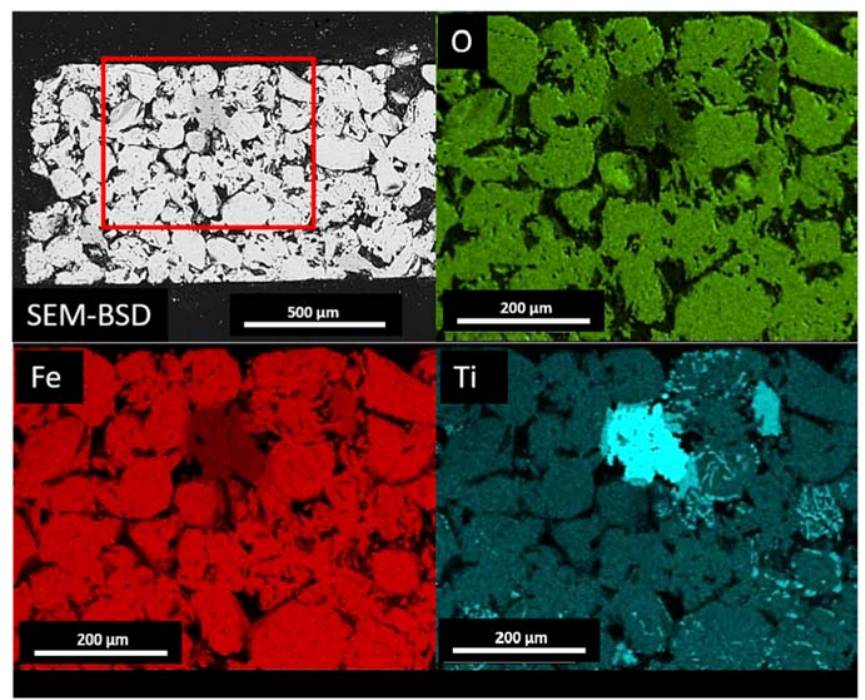

Figure 4. SEM-BSD image (top left) and corresponding EDS elemental maps of oxygen (top right), Iron (bottom left) and titanium (bottom right) of the sintered pellet before reduction.

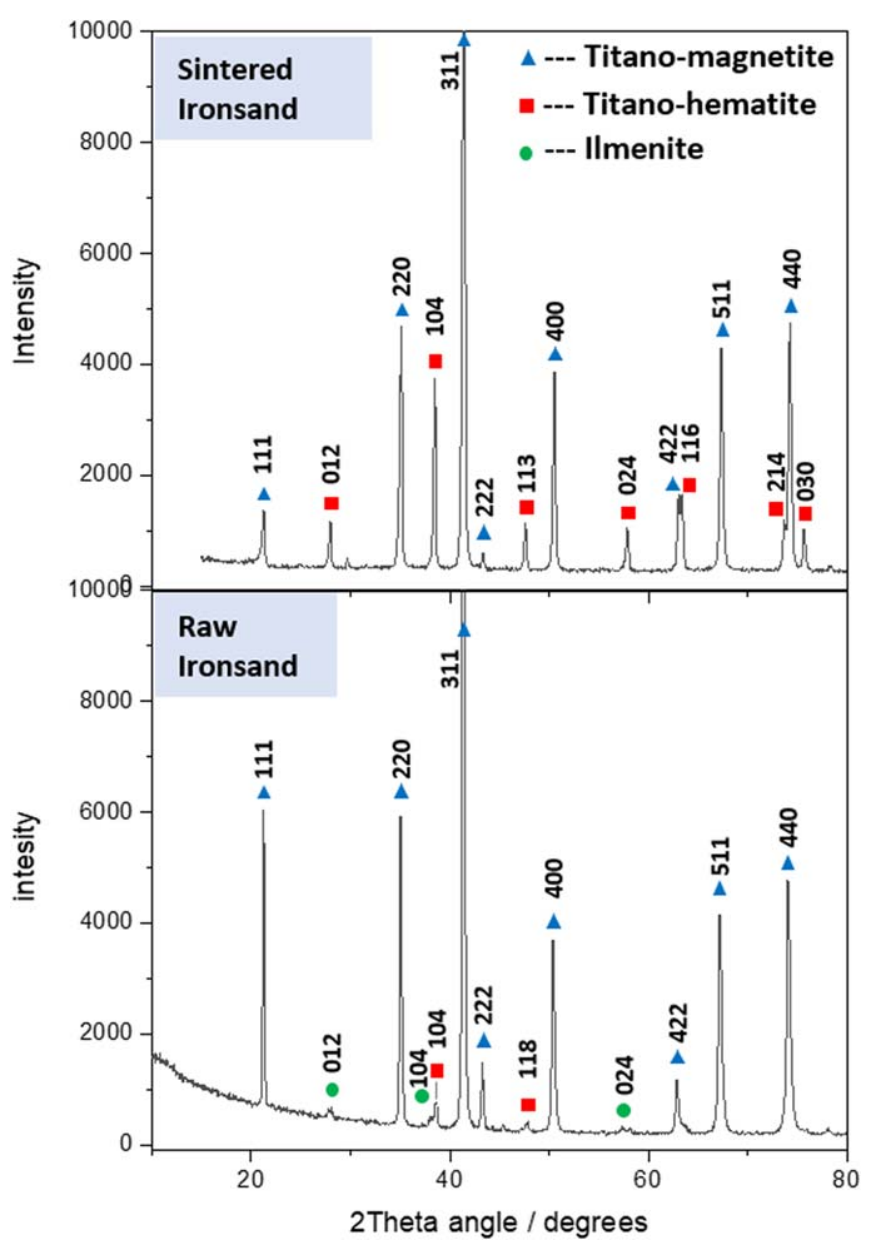

Figure 5. XRD-patterns for raw NZ ironsand (bottom) and sintered ( $1300{ }^{\circ} \mathrm{C}, 2 \mathrm{~h}$ under argon) pellet (top). The pellet sample was ground to a powder to ensure this data is representative of the full pellet volume. 


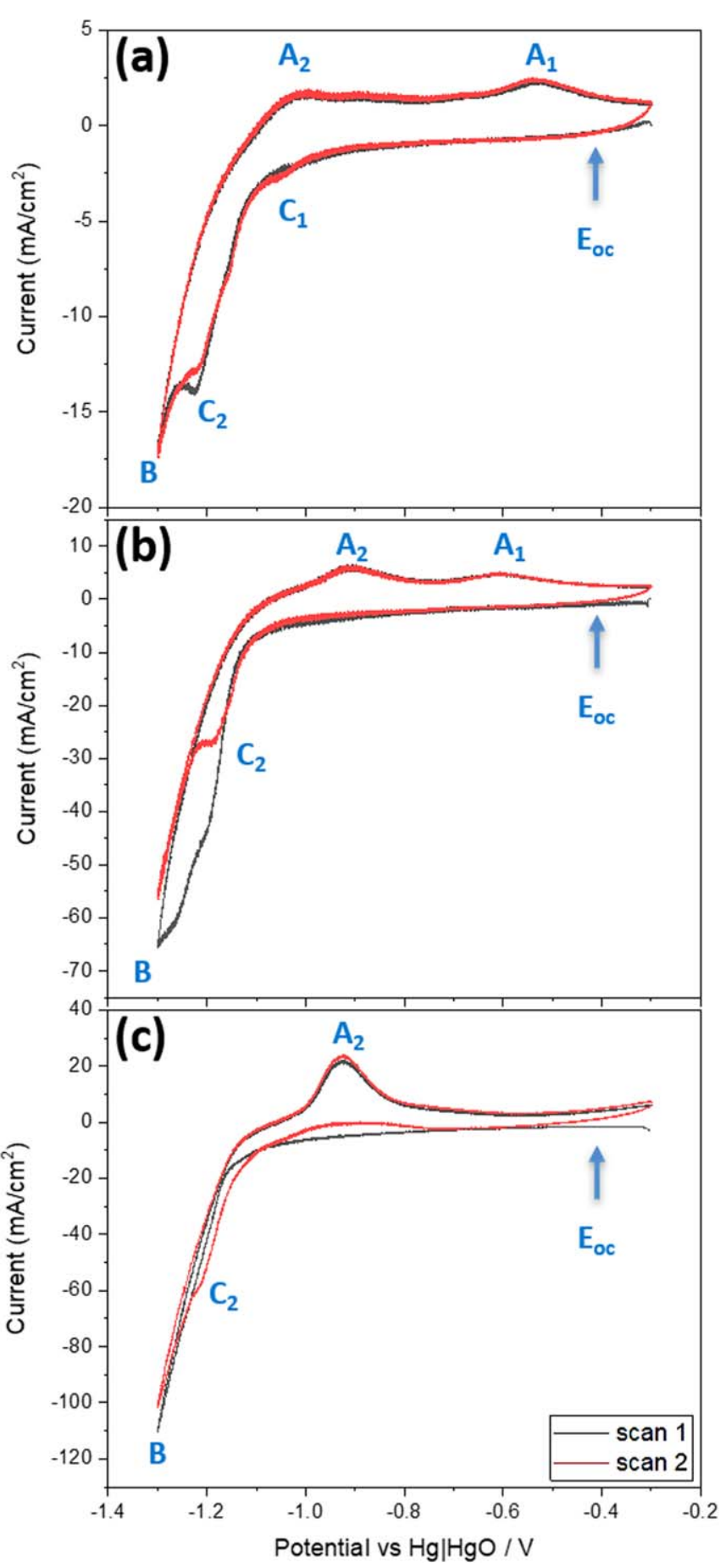

Figure 6. C-V curves (scan rate of $20 \mathrm{mV} \mathrm{s}^{-1}$ ) obtained from sintered ironsand (pellet) electrodes in $\mathrm{NaOH} 50 \mathrm{wt} \%$ solution at temperatures of: (a) $50{ }^{\circ} \mathrm{C}$; (b) $80{ }^{\circ} \mathrm{C}$; and (c) $110{ }^{\circ} \mathrm{C}$.

diffusion rates also both increase with temperature, such that a combination of these effects probably contribute to this strong current density enhancement with temperature [44-46].

\subsection{Electro-reduced ironsand pellets}

A pellet reduced at $-1.0 \mathrm{~A}$ for $2 \mathrm{~h}$ was then removed from the cell and examined. Figures $7(\mathrm{a})$ and (b) show SEM images of the resulting electro-reduced surface. The particulate structure of the unreduced pellet has been replaced by a coalescent network of metallic globules. XRD analysis (figure 7(c)) shows that $\mathrm{BCC} \alpha$-iron is now the major phase present at this surface, and that the original titano-magnetite (spinel) phase is undetectable. Note that XRD peaks are sharp in this figure because this is high purity elemental iron in stark contrast with previous figure where the peaks are broad due to the presence of impurities in the inhomogeneous natural occurring mineral sand. 


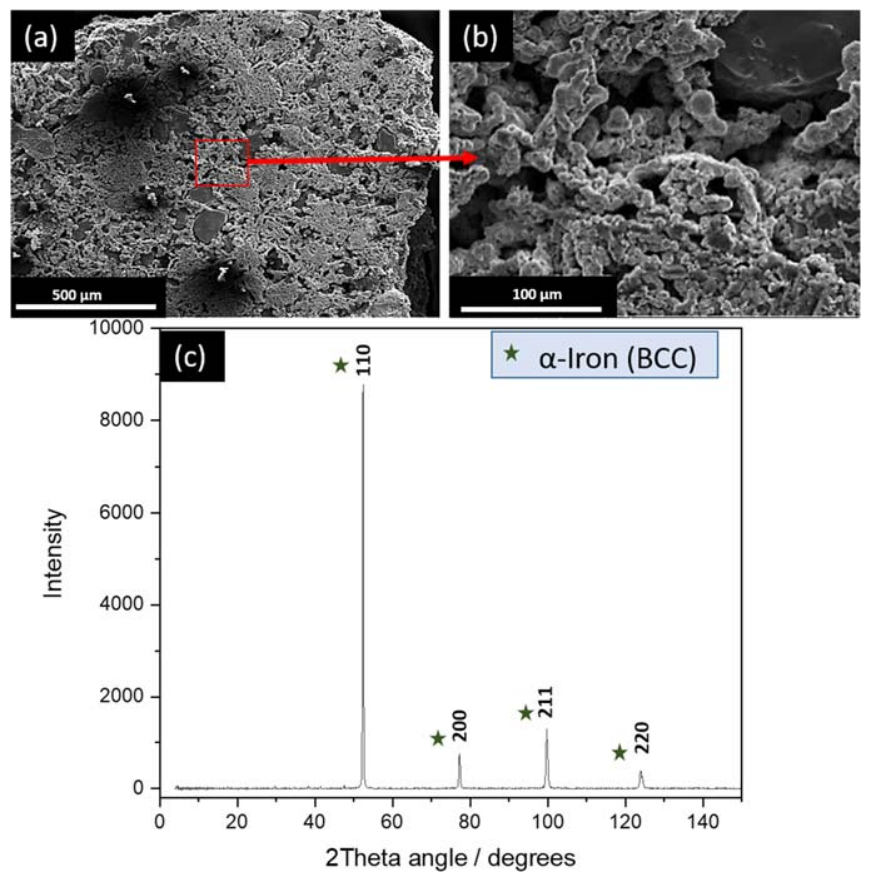

Figure 7. Surface of pellet after electro-reduction in $50 \mathrm{wt} \% \mathrm{NaOH}, 110{ }^{\circ} \mathrm{C}, 2 \mathrm{~h}$ and $-1.0 \mathrm{~A} \mathrm{~cm}^{-2}$. (a) Low magnification SEM image. (b) High magnification SEM image of highlighted area. (c) XRD pattern obtained from pellet surface, green stars indicate peaks corresponding to $\alpha$-iron.

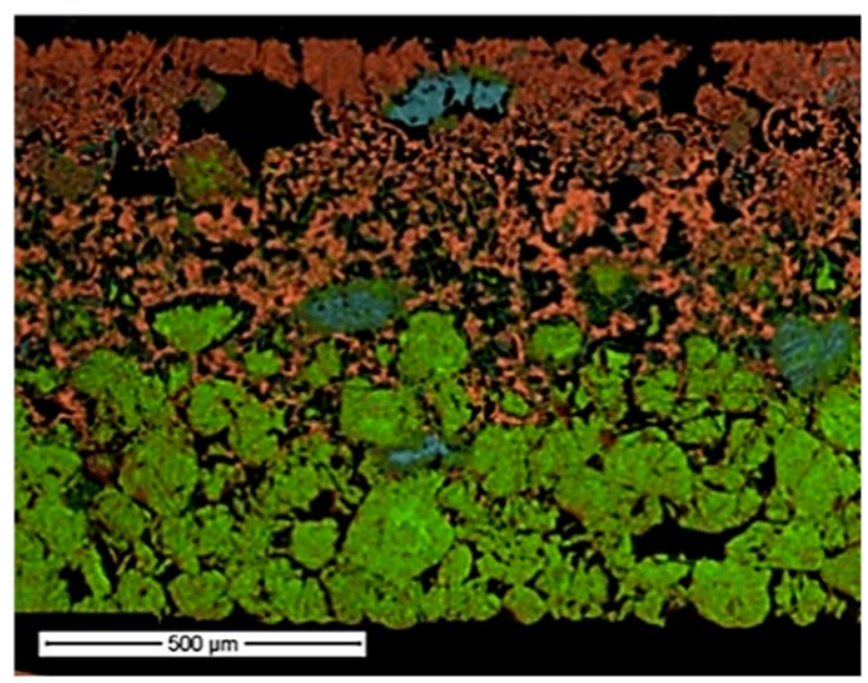

Figure 8. Overlay image of element maps for Fe (orange), Ti (blue) and $\mathrm{O}$ (green) from EDS mapping of a cross-sectioned ironsand pellet reduced for $16 \mathrm{~h}$ at $1 \mathrm{~A} \mathrm{~cm}^{-2}$.

The removal of oxygen from the metal surface layer is also clearly evident in elemental maps of a crosssectioned electro-reduced pellet. Figure 8 shows an element overlay image for oxygen, iron and titanium obtained via EDS-mapping. The top part in this image represents the electrolyte-pellet interface, whilst the bottom of the image was closest to the electrode during electroreduction. A metallic iron surface layer (orange) can clearly be seen from which oxygen has been almost entirely depleted. Exceptions to this are a few particles containing very high levels of $\mathrm{Ti}$, and a few small elongated lamella (green), which are discussed further in the next section.

Figure 8 also shows that the original particulate structure of the pellet has been largely destroyed in the metallic region and replaced by a porous dendritic interconnected network. This increase in porosity is due to the change in density from the initial TTM phase $\left(4800-5300 \mathrm{~kg} \mathrm{~m}^{-3}\right)$ [33] to iron metal $\left(7200 \mathrm{~kg} \mathrm{~m}^{-3}\right)$. Progressing deeper into the pellet, a clear reaction front interface can be observed separating the electro-reduced 


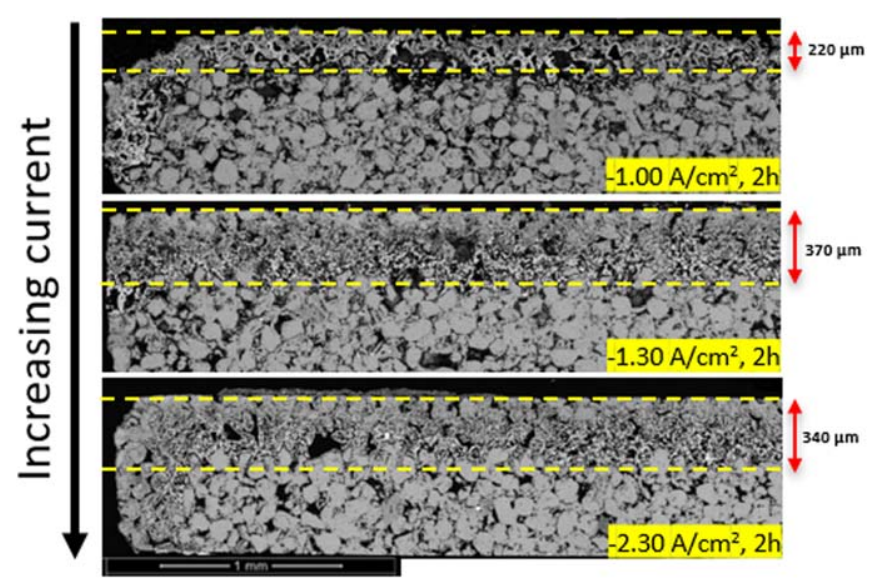

Figure 9. SEM-BSE images of the cross section of ironsand pellets. Effect of current density and time on the depth of reaction front.

Table 2. Reduction conditions, and the depth of the reaction front for samples 1 to 7 . All experiments were all performed in $50 \mathrm{wt} \% \mathrm{NaOH}$ at $110^{\circ} \mathrm{C}$.

\begin{tabular}{llcccc}
\hline$\#$ & Time (h) & Current (A) & Electrode Current density A cm & Total charge delivered C cm & Reaction front depth $(\mu \mathrm{m})$ \\
\hline 1 & 2 & -0.5 & 1.00 & 7157 & 220 \\
2 & 2 & -1.0 & 1.30 & 9171 & 370 \\
3 & 2 & -1.8 & 2.30 & 16509 & 340 \\
4 & 4 & -0.3 & 0.40 & 5503 & 410 \\
5 & 16 & -0.8 & 1.00 & 58700 & 440 \\
6 & 17 & -1.0 & 1.30 & 77961 & 470 \\
7 & 1.8 & -1.8 & 2.30 & 53408 & 390
\end{tabular}

metallic region (orange) from the oxygen rich TTM region (green). This lower region appears to be unaffected by the electroreduction process, with the original particle morphology still clearly apparent.

In order to investigate the progression of this reaction front in more detail, a series of ironsand pellets were reduced for different durations at various constant current densities, under the conditions given in table 2.

Figure 9 shows back-scatter (BSE) SEM images of cross-sections of a subset of these samples, each reduced for $2 \mathrm{~h}$ at increasing current levels. In each case the reaction front formed between the metallic iron layer and the unreacted inner TTM zone can again be clearly seen. Overall, the depth of this reaction front is observed to increase with increasing total charge delivered to the electrodes. However, once the front reaches a depth of approx. $350 \mu \mathrm{m}$, further progress is significantly slowed, and applying further charge has little effect on the remaining unreduced iron oxides in the pellet.

This stagnation behaviour may be explained by the thin planar pellet electrode geometry used for these experiments. As the electroreduction of the pellet progresses, the outer metallic iron layer forms at all surfaces, and including the outer edges of the $1.5 \mathrm{~mm}$ thick pellet. Eventually the iron layer at each edge extends far enough to meet with the backside electrode. Evidence for this 'edge shorting effect' can be seen in the top and bottom images in figure 9, which both show the left-hand edges of the respective pellets. In each case, the metallic iron layer is observed to continue down the left-hand edge of the pellets towards the backside electrode. Once the metallic iron layer meets the back electrode it will 'short-circuit' the unreduced region remaining in the centre of the pellet (as the unreduced oxide has a much lower electrical conductivity). From this point onwards, charge is then transferred directly from the back electrode into the iron-electrolyte interface, leading to the preferential formation of hydrogen at this interface [4], rather than reduction of iron at the interior of the pellet.

\subsection{Morphology and phase development}

In general, lower current densities are observed to produce a denser metallic network within the electro-reduced layer, whilst higher currents produce a more porous dendritic structure. At all current densities it is notable that small oxide inclusions remain within the electro-reduced layer which are not converted to iron metal. These residual oxides are found to be enriched in titanium content. This is because the initial unreduced ironsand contains approx. 4 wt. \% $\mathrm{Ti}$, which cannot be reduced to titanium metal in an $\mathrm{NaOH}$ solution. As such Ti-oxides must be exsolved during the electro-reduction process, either into the electrolyte solution or as phase-segregated solids. 

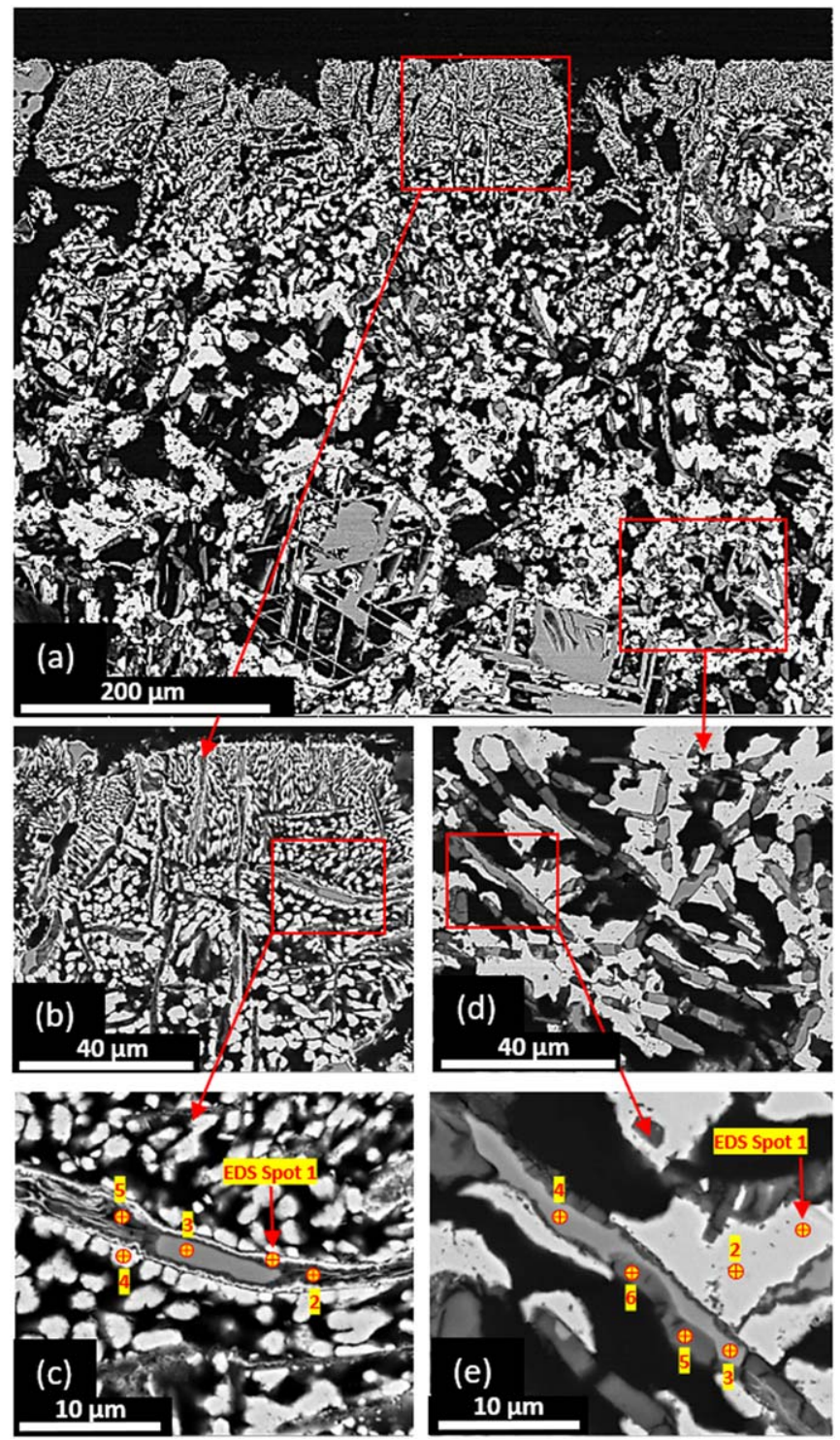

Figure 10. (a) SEM-image of cross section of ironsand pellet (sample 5) after reduction at $-1.8 \mathrm{~A} \mathrm{~cm}^{-2}$ in $50 \mathrm{wt} \%$ aq. $\mathrm{NaOH}$ at $110{ }^{\circ} \mathrm{C}$ for 16 h. (b) Image of reduced iron and titanium-rich inclusions occurring near the pellet surface (c) Magnified image of inclusion and surrounding metal from image b, showing locations of EDS spot analyses. (d) Image of titanium rich inclusions and surrounding iron from deeper within pellet, near the reaction front. (e) Magnified image of inclusion and surrounding metal from image $d$, showing locations of EDS spot analyses.

Figure 10 shows SEM images of residual oxide inclusions found within the electro-reduced layer, after extended electroreduction at $-1.8 \mathrm{~A} \mathrm{~cm}^{-2}$. Magnified regions are shown both from near the pellet surface (figures 10(b) and (c)), and near the reaction front boundary (figures 10(d) and (e)). Table 3 and figure 11 show accompanying EDS analyses of these images. Spot analysis confirms that Ti levels in the metallic iron is low, with detected levels of $\sim 1 \%$ Ti possibly being due to nanoscale oxide inclusions. As this is insufficient to account for all of the titanium originally present, we surmise that some Ti migration has occurred into the unreduced material during the reaction. This has stabilised these residual oxides to further electrochemical reduction. The oxide inclusions are observed throughout the electro-reduced layer, but there are clear differences between the oxide inclusions observed at the surface and those deeper inside the pellet.

Oxide inclusions observed deep within the pellet comprise two distinct oxide phases. These can be distinguished in figure 10 (e) as regions of either darker or lighter grey contrast. The lighter phase may be Tienriched TTM, as the measured Ti/Fe ratios lie within the titanium-saturation limit $(x=1)$ of the $\mathrm{Fe}_{3-x} \mathrm{Ti}_{x} \mathrm{O}_{4}$ spinel [see points 3 and 4 in table 3(ii)]. By contrast, the Ti/Fe ratio in the darker phase is much higher [points 5 and 6 in table 3(ii)]. The sodium level in the darker phase is also substantially higher than the background level. These observations are consistent with the formation of a sodium iron titanate phase, such as $\mathrm{Na}_{x} \mathrm{Fe}_{x} \mathrm{Ti}_{2-x} \mathrm{O}_{4}$ $[47,48]$. This is forming from the outer edges of the inclusion, through taking up additional $\mathrm{Na}$ from the $\mathrm{NaOH}$ electrolyte. 

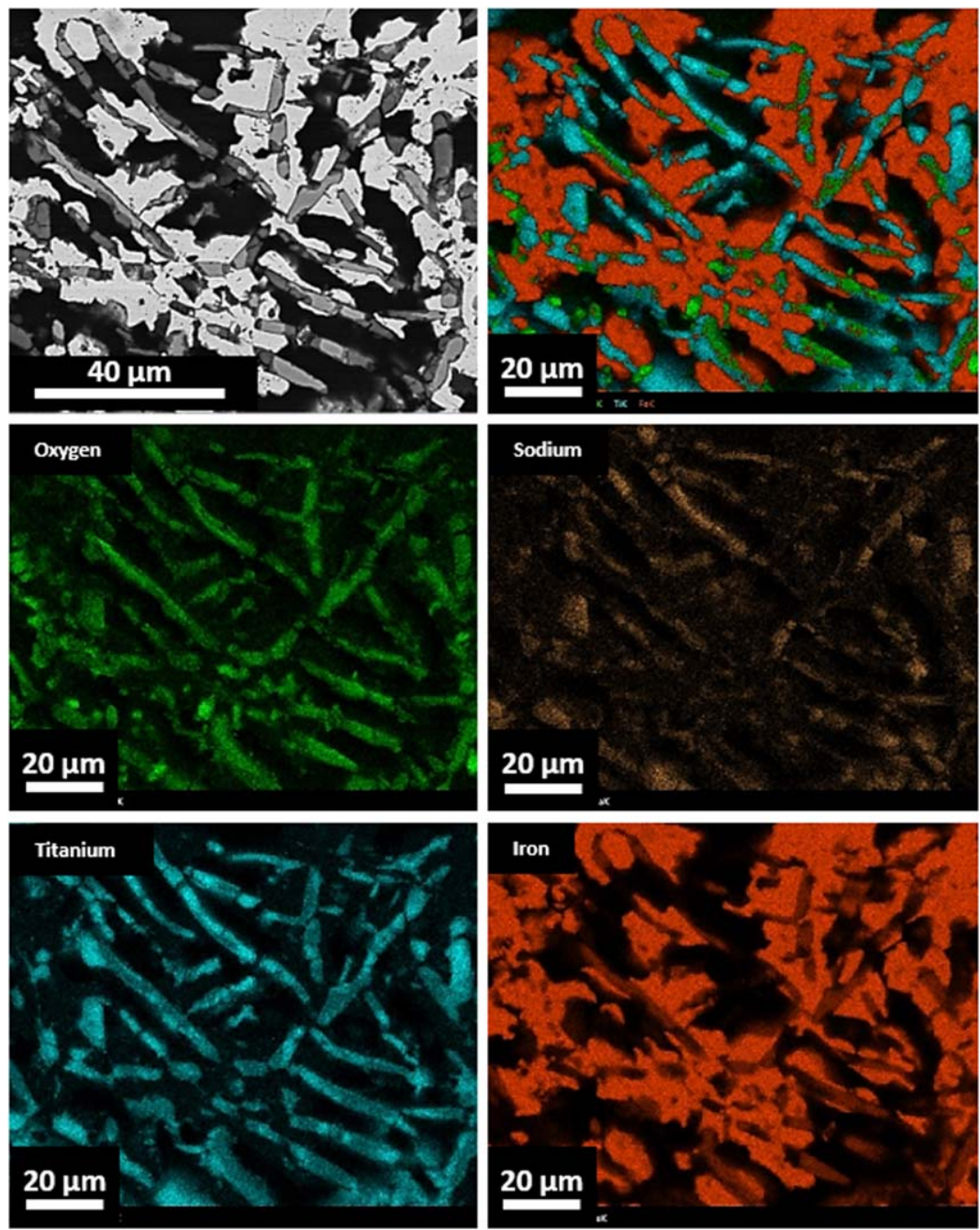

Figure 11. EDS elemental maps of oxygen (green), sodium (brown), titanium (blue) and iron (red) for oxide inclusions shown in figure $10(d)$.

Table 3. Quantitative EDS point analysis of lamellae and surrounding metal in the electrochemically reduced iron sand pellet.

\begin{tabular}{lccccccc}
\hline Spot \# & $\mathrm{O}$ & $\begin{array}{c}\mathrm{Na} \\
\text { (i) Points from }\end{array}$ & $\begin{array}{c}\mathrm{Mg} \\
\text { figure }\end{array}$ & $\begin{array}{c}\mathrm{Ti} \\
\text { (c), }\end{array}$ & $\begin{array}{c}\mathrm{Fe} \\
\text { Top layer composition (atomic \%) }\end{array}$ & $\mathrm{Ti} / \mathrm{Fe}$ & $\mathrm{Na} / \mathrm{Fe}$ \\
\hline 1 & 46.1 & 3.2 & 0.7 & 10.4 & 39.4 & 0.26 & 0.08 \\
2 & 40.8 & 9.1 & 1.6 & 10.6 & 37.6 & 0.28 & 0.24 \\
3 & 51.9 & 2.9 & 1.5 & 7.7 & 35.0 & 0.22 & 0.08 \\
4 & 10.3 & 0 & 0 & 1.9 & 87.7 & 0.02 & -0.47 \\
5 & 46.2 & 13.0 & 1.6 & 11.1 & 27.9 & 0.40 & \\
\hline
\end{tabular}

(ii) Points from figure 10(e), Interphase layer composition (atomic \%)

\begin{tabular}{lrllllll}
\hline 1 & 6.9 & 4.6 & 0 & 1.1 & 87.2 & 0.01 & 0.05 \\
2 & 7.7 & 5.0 & 0 & 1.5 & 85.7 & 0.01 & 0.06 \\
3 & 53.0 & 4.3 & 1.6 & 9.2 & 30.8 & 0.30 & 0.14 \\
4 & 53.5 & 2.1 & 1.7 & 8.1 & 33.4 & 0.24 & 0.06 \\
5 & 60.2 & 8.9 & 2.6 & 17.7 & 10.1 & 1.75 & 0.88 \\
6 & 61.0 & 7.8 & 2.4 & 16.7 & 11.3 & 1.47 & 0.69 \\
\hline
\end{tabular}

The oxide inclusions nearer the surface have experienced a longer period of local reduction, as the reaction front moved pass these features at an earlier time. Unlike the deeper-occurring oxides, these 'older' inclusions now show a pronounced outer shell which separates the interior oxide from the surrounding iron metal (figure 10(c)). This shell-layer shows elevated levels of both titanium and sodium [see points 2 and 5 in table 3(i)] 


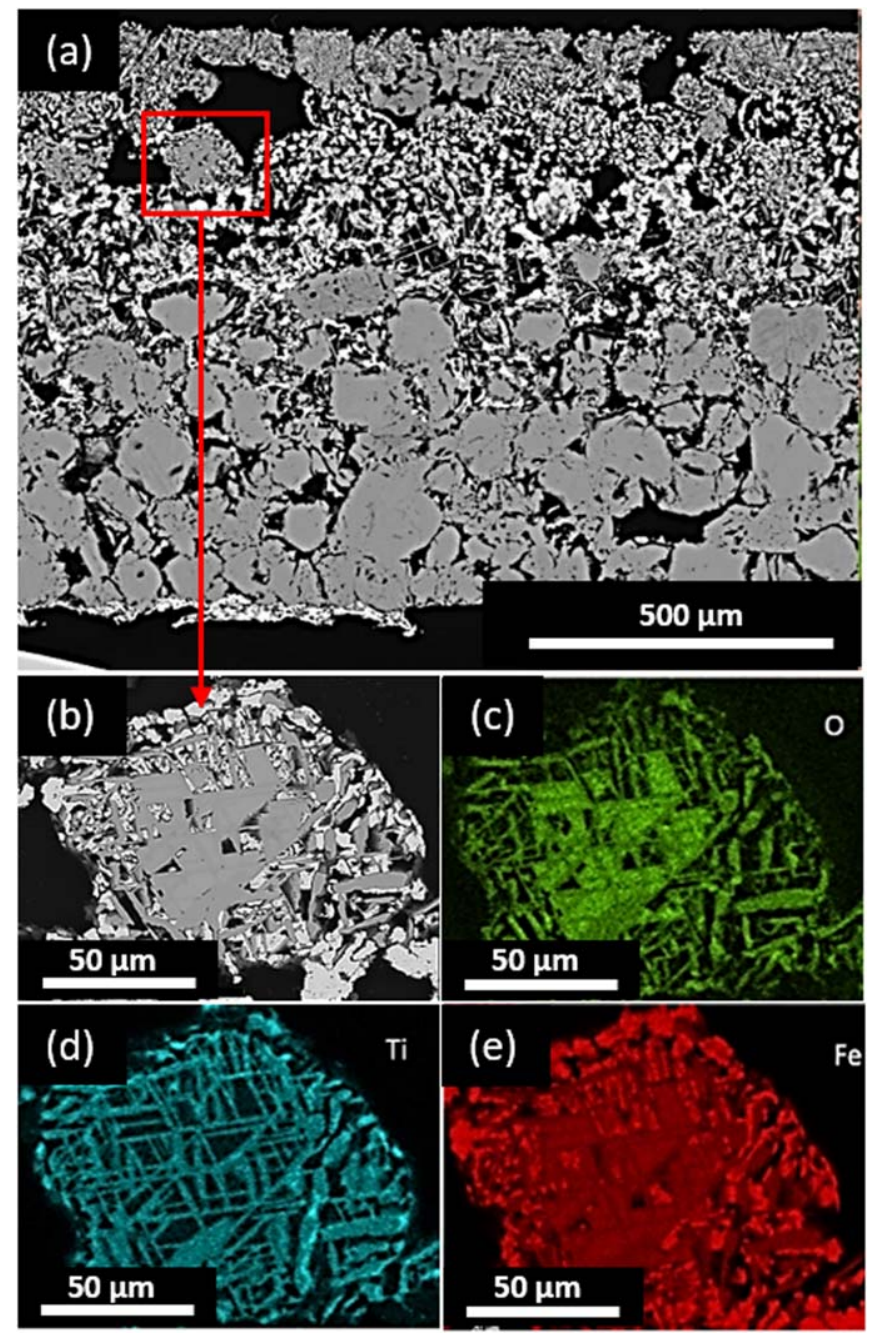

Figure 12. Back-scatter SEM image of cross section of ironsand pellet (sample 5) after reduction at $-1.8 \mathrm{~A} \mathrm{~cm}^{-2}$ in $50 \mathrm{wt} \%$ aq. $\mathrm{NaOH}$ at $110^{\circ} \mathrm{C}$ for $16 \mathrm{~h}$. SEM-BS image of partially reduced iron sand particle with exsolved TTH lamella. Bottom images show EDS maps of this particle for: $\mathrm{Ti}$ (blue), $\mathrm{Fe}$ (red) and $\mathrm{O}$ (green).

and has probably formed from the $\mathrm{Na}-\mathrm{Ti}-\mathrm{Fe}-\mathrm{O}$ phase discussed above. However, the $\mathrm{Ti} / \mathrm{Fe}$ ratio is substantially lower in this shell material, suggesting that titanate species may have leached into the electrolyte over time [49]. The presence of void-like features between the shell and the enclosed interior oxide provide further evidence that some of this material has been leached.

A common feature of all of the observed oxide inclusions is that they adopt an elongated shape, with some preferential local alignment. This morphology can be understood by examining the partially reduced ironsand particles found nearest to the reaction front. Figure 12 shows one such particle, where the particle surface has been largely converted to metallic iron (white), but the inner region remains in the oxide phase (light grey). This 'shrinking core' behaviour occurs because the electrochemical reduction takes place at the electrolyte surface, which is yet to propagate to the inner core of the particle.

EDS maps (Figures 12(b)-(d)) show that the unreduced region of the particle contains multiple Ti-enriched lamellae. These are the naturally occurring TTH lamella found in the unreduced ironsand. At the surface, the reaction appears to be selective; converting the TTM matrix to iron metal but leaving some of the Ti-enriched lamella behind. Close examination of both figures 10 (a) and 12(a) reveal a substantial number of similar fine lamella relics are present in the lower portion of each image. It appears that these lamellae form a nucleus for further growth of residual oxides, thickening over time through the accretion surrounding exsolved material. As a result, the residual oxides retain an elongated shape, and remain approximately aligned with the crystal twinning-planes of the parent ironsand particle. 


\section{Conclusion}

We have demonstrated the electrochemical reduction of sintered titano-magnetite ironsand cathodes in concentrated $\mathrm{NaOH}$ electrolyte to produce $\alpha$-iron. Reduction starts at the surface and proceeds inwards, forming a porous metallic layer with a well-defined reaction front. The increased porosity is a result of the volume reduction which accompanies the removal of oxygen from the parent oxide.

The electro-reduction process is selective for iron, with unreduced titanium-bearing oxides being exsolved as residual solid inclusions in the metallic layer. These inclusions appear to nucleate from TTH lamellae within the original ironsand, which thicken as the reaction progresses. EDS analysis shows that at least two distinct phases are formed within the oxide inclusions, a Fe-Ti-O oxide likely corresponding to Ti-enriched TTM, and a sodium iron titanate phase formed through uptake of $\mathrm{Na}^{+}$from the electrolyte solution. After extended reaction times, a sodium titanate outer layer is observed around each oxide inclusion.

These laboratory-scale results demonstrate that solid-state electro-reduction of titanomagnetite ironsand is feasible, and a potential route for the low- $\mathrm{CO}_{2}$ production of iron from this naturally occurring ore. However, the sintered cathode approach explored here exhibits very low faradaic efficiencies and is not easily scalable, so industrial application would require an alternative approach. The slurry reduction method $[5,11,19,25]$ offers more promise in this regard and will be the subject of future work. In that case, the expulsion of solid titaniumbearing oxides from the metallic iron may prove particularly advantageous, as this could result in these metallurgically-troublesome inclusions being rejected from the final electrodeposited metal product.

\section{Acknowledgments}

This work was supported by funding from NZ MBIE Endeavour fund, Grant No. RTVU1404. The authors wish to thank Sarah Spencer for assistance with SEM microscopy and Martin Ryan for assistance with XRD measurements undertaken during this work.

\section{ORCID iDs}

Tanzeel Arif (iD https://orcid.org/0000-0002-4713-7800

Brian Monaghan (iD https://orcid.org/0000-0002-6341-3588

Chris W Bumby (i) https://orcid.org/0000-0001-8555-2469

\section{References}

[1] Fischedick M et al 2014 Chapter10 inClimate Change 2014: Mitigation of Climate Change. Working Group III Contribution to the Fifth Assessment Report of the Intergovernmental Panel on Climate Change (Cambridge, UK) (Cambridge University Press)

[2] Quader M A, Ahmed S, Dawal S Z and Nukman Y 2016 Renew. Sust. Energ. Rev. 55 537-49

[3] Xu C and Da-qiang C 2010 J. Iron and Steel Res. Intl. 17 01-07

[4] Izaki M 2010 Electrodeposition of iron and iron alloys in ed M Schlesinger and M Paunovic (eds)Modern Electroplating (Hoboken, New Jersey: Wiley) pp 309-21

[5] Estelle A T C 1918 Process of electrolytically producing iron and alloys thereof GB Patent 159906

[6] Havlík T 2008 Extracting metals from solutions Hydrometallurgy: Principles and Application (Cambridge, England: Woodhead Publising Limited) pp 255-289

[7] Hsu P et al 2008 J. Electrochem. Soc. 155 D400-7

[8] Ferreira N M, Kovalevsky A V, Ferro M C, Costa F M and Frade J R 2016 Ceramics International $4211070-6$

[9] Sadoway D R 1995 J. Mater. Res. $10487-92$

[10] Abdelkader A M, Kilby K T, Cox A and Fray D J 2013 Chem. Rev. $1132863-86$

[11] Yuan B, Kongstein O E and Haarberg G M 2009 J. Electrochem. Soc. 156 D64-9

[12] Ivanova Y A, Monteiro J F, Teixeira L B, Vitorino N, Kovalevsky A V and Frade J R 2017 Material and Design 122 307-14

[13] Gorbunova K M and Liamina L I 1966 Electrochim. Acta. 11 457-67

[14] Tokushige M, Kongstein O E and Haarberg G M 2013 ECS Trans. 50 103-14

[15] Taylor P R, Shuey S A, Vidal E E and Gomez J C 2006 Mining, Metallurgy \& Exploration 23 80-6

[16] Hukkanen E and Walden H 1985 Intl. J. Mineral Processing 15 89-102

[17] Pang Z, Lu X, Jiang Y, Ling J and Yan Z 2020 Metallurgical and Materials Transactions B 51 722-31

[18] Sun H, Adetoro A A, Wang Z, Pan F and Li L 2016 ISIJ International 56 936-43

[19] Allanore A, Lavelaine H, Valentin G, Birat J P and Lapicque F 2008 J. Electrochem. Soc. 155 E125-9

[20] Allanore A, Lavelaine H, Valentin G, Birat J P, Delcroix P and Lapicque F 2010 Electrochemica Acta. 55 4007-13

[21] Monteiro J F, Ivanova Y A, Kovalevsky A V, Ivanou D K and Frade J R 2016 Electrochim. Acta. 193 284-92

[22] Caldas C A, Lopes M C and Carlos I A 1998 J. Power Sources 74 108-17

[23] Zou X, Gu S, Lu X, Xie X, Lu C, Zhou Z and Ding W 2015 Metall. Mater. Trans. B 46 1262-74

[24] Wang Q, Zhu Y, Wu Q, Gratz E and Wang Y 2015 RSC Advances 5 5501-7

[25] Feynerol V, Lavelaine H, Marlier P, Pons M N and Lapicque F 2017 J. Appl Electrochem. 47 1339-50

[26] Maihatchi A, Pons M N, Ricoux Q, Goettmann F and Lapicque F 2020 J. Electrochem. Sci. Eng. $1095-102$

[27] Ziernniak S E, Jones M E and Combs K E S 1995 J. Solution Chem. 24 837-8 
[28] Fray D J, Chen G Z and Farthing T W 2000 Nature 407 361-4

[29] Park E and Ostrovski O 2003 ISIJ International 43 1316-25

[30] Lilova K I, Pearce C I, Gorski C, Rosso K M and Navrotsky A 2012 American Mineralogist 97 1330-8

[31] Li G, Jin X, Wang D and Chen G Z 2009 J. Alloys and Compounds 482 320-7

[32] Wang Z, Pinson D, Chew S, Rogers H, Monaghan B J, Pownceby M I, Webster N A S and Zhang G 2016 Metall. Mater. Trans. B 47 330-4

[33] Brathwaite R L, Gazley M F and Christie A B 2017 J. Geochemical Exploration 178 23-34

[34] Zhang A, Monaghan B J, Longbottom R J, Nusheh M and Bumby C W 2020 Metallallurgical and Materials Transactions B $51492-504$

[35] Lawton D C and Hochstein M P 1980 Geophysics 45 394-402

[36] Geng C, Sun T, Yang H, Ma Y, Gao E and Xu C 2015 ISIJ International 55 2543-9

[37] Zou X, Gu S, Cheng H, Lu X, Zhou Z, Li C and Ding W 2015 J. Electrochem. Soc. 162 D49-55

[38] Prabowo S W, Longbottom R J and Monaghan B J 2019 Metall. and Materi. Trans B 50 1729-44

[39] Wright J and Lovering J 1965 Mineralogical Magazine and Journal of the Mineralogical Society 35 604-21

[40] Ketteler G, Weiss W, Ranke W and Schlogl R 2001 Physical Chemistry Chemical Physics $31114-22$

[41] Amaral S T, Martini E M A and Müller I L 2001 Corros. Sci. 43 853-79

[42] Zhang H and Park S M 1994 J. Electrochem. Soc. 141 718-24

[43] Ciobanu M, Wilburn J P, Krim M L and Cliffel D E 2007 Fundamentals Handbook of Electrochemistry ed C. G. Zoski (Oxford, UK: Elsevier) pp 3-29

[44] Amaral S T and Müller I L 1999 Corros. Sci. 41 759-71

[45] Bouzek K, Rousar I, Bergmann H and Hartwig K 1997 J. Electroanal. Chem. 425 125-37

[46] Wieckowski A and Ghali E 1985 Electrochim. Acta 30 1423-31

[47] Mumme W G and Reid A F 1968 Acta Cryst. B 24625

[48] Shukaev I L, Butova V V, Chernenko S V, Pospelov A A, Shapovalov V V, Guda A A, Aboraia A M, Zahran H Y, Yahia I S and Soldatov A V 2020 Ceramics International 46 4416-22

[49] Li X, Yu S, Liu N, Chen Y, Qi T, Zhou Q, Liu G and Peng Z 2014 Hydrometallurgy 147 73-8 